\title{
Effect of E-Learning on the Academic Performance of Third Year Students in Statistics at Mukuba University
}

\author{
Gerald Banda ${ }^{1 \star}$, Frank Patson Tailoka ${ }^{1}$, Elias Muma ${ }^{1}$
}

\author{
${ }^{1}$ Mukuba University, ZAMBIA \\ *Corresponding Author: gerald1banda@gmail.com
}

Citation: Banda, G., Tailoka, F. P., \& Muma, E. (2021). Effect of E-Learning on the Academic Performance of Third Year Students in Statistics at Mukuba University. Journal of Mathematics and Science Teacher, 1(2), em004. https://doi.org/10.29333/mathsciteacher/11277

\begin{tabular}{|c|c|}
\hline ARTICLE INFO & ABSTRACT \\
\hline Received: 31 May 2021 & A mode of teaching where students receive all information passively from a lecturer is ineffective in fostering of \\
\hline Accepted: 9 Sep. 2021 & $\begin{array}{l}\text { conceptual understanding of statistics. One mode of teaching which engages learners in the learning process of } \\
\text { statistics is e-learning. This study was therefore, designed to determine the effect and challenges of e-learning on } \\
\text { students at Mukuba University. The study employed quasi-experimental design. Sample for the study consisted of } \\
60 \text { third year students of mathematics studying statistics. Self-made questionnaire and statistics performance } \\
\text { tests were used to collect data for the study. Students in the experimental group learnt Gamma and Beta Function, } \\
\text { and Probability Distributions of Function of Random Variable using E-Learning approach while students in the } \\
\text { control group learnt Gamma and Beta Function, and Probability Distributions of Function of Random Variable } \\
\text { using conventional learning approach. Data for the study was analyzed using independent sample t-test statistics. } \\
\text { The null hypothesis }\left(H_{0}\right) \text { was tested at } 5 \text { percent significance level. The findings of the study revealed that E- } \\
\text { Learning approach improved students' academic performance. Based on this, this study recommended that E- } \\
\text { Learning should be used as an alternative method in teaching of statistics. }\end{array}$ \\
\hline
\end{tabular}

Keywords: e-learning, academic performance, quasi-experimental

\section{INTRODUCTION}

A mode of teaching where students receive information passively from a lecturer is ineffective in fostering understanding of statistics, it is necessary to pass a system where students are actively involved in the learning process. Because of this, there is need to shift from the traditional-based method of teaching to one that is learner-based in which learners actively participate in the learning process of statistics (Auer \& Thrasyvoulos, 2018). At Mukuba University, students are predominantly taught statistics using lectures which are usually supplemented by textbooks and demonstration. As a result, the lecturer usually initiates the learning process. Given that direct instruction traditional-based teaching does not develop conceptual understanding of the subject. The academic performance of students in statistics has been poor over the years. For instance, in Introduction to Probability and Statistics (MAT 250) among second year students at Mukuba University out of ninety-four candidates who sat for MAT 250 examination in the 2014 academic year, only forty-eight candidates representing 51 percent passed the course while 49 percent failed the course. Similarly, out of seventy-nine candidates who sat for MAT 250 examination in the 2015 academic year only forty-two candidates representing 53 percent passed the course while 47 percent failed the course. With regard to 2019 academic year, forty-two candidates sat for Mathematical and Applied Statistics (MAT 350) examination. Fourteen candidates passed and this represents 33 percent and 67 percent failed the course. Traditional-based teaching of statistics is therefore, not helping in building the understanding of students in statistics. The $21^{\text {st }}$ century generation is better in being actively participating in the learning process; actively responding to the comments of their lecturers and their students as they manage the process of collaborative inquiry on their own using e-learning can be defined as a learning utilizing electronic technologies to access educational curriculum outside of a traditional classroom (College, 2020). This model of learning is learner-based. In short term Elearning can be defined as teaching using online. In this case topics were taught using internet and students were assessed online. In e-learning, teaching can be based in or out of classroom and internet forms the major component of e-learning. E-learning, or electronic learning, is the delivery of learning and training through digital resources (Lawless, 2018). Although e-learning is based on formalized learning, it is provided through electronic devices such as computers, tablets and even cellular phones that are connected to the internet and this makes it easy for users to learn anytime, anywhere, with few, if any, restrictions (Lawless, 2018). Zoom and WhatsApp are some of the software used in e-learning to teach statistics topics for three months. The study investigated the effect and challenges of e-learning on the third year Mathematics students at Mukuba University. 


\section{Objectives of the Study}

The study sought to investigate the potential for e-learning to improve students' scores in statistics in an interactive cycle of testing and developing research instruments for use in an examination. The following were the objectives of the study:

(i) To determine the effect of e-learning on students' performance in Statistics.

(ii) To determine the challenges involved in the implementation of e-learning in teaching statistics at Mukuba University.

\section{Research Questions}

The study was guided by the following research questions:

(i) What is the effect of e-learning on students' academic performance in Statistics?

(ii) What are the challenges involved in the implementation of e-learning in teaching statistics at Mukuba University?

\section{Hypothesis}

The following hypothesis guided the study and was tested at 0.05 confidence level of significance.

\section{Null Hypothesis}

$\boldsymbol{H}_{\mathbf{0}}$ : There is no statistically significant difference in performance of third year students in statistics between students who were taught using e-learning Approach and students taught using Conventional Learning Approach.

\section{Alternative Hypothesis}

$\boldsymbol{H}_{1}$ : There is a statistically significant difference in performance of third year students in Statistics between students who were taught using e-learning Approach and students taught using Conventional Learning Approach.

\section{The Significance of the Study}

The significance of the study was twofold; first, it anticipated that to provide alternative method of teaching statistics to the traditional-based ones. Second, it was anticipated that the study would raise students' motivation to study statistics as they interact with various e-learning platforms. It is hoped that the results of the study will assist students at Mukuba University who are studying statistics to incorporate the findings of the study in their classes where they are working.

\section{THEORETICAL FRAMEWORK}

For effective learning to take place, teamwork and cooperation among students is required. This does not only apply to pupils in primary and secondary schools, but also students in higher learning institutions of education. According to Davidson and Major (2014), adopting e-learning would enable the students to learn from each other; this enables them to immensely gain interpersonal skills through group participation. Furthermore, e-learning enables the students to have broader understanding of the course since they are able to collaborate in the learning process (Davidson \& Major, 2014). The study looked at the theory of Levy Vygotsky of sociocultural theory of human learning as the main guide of the study. According to Vygotsky (1978), learning is a social process and the origination of human intelligence in society or culture. According to Vygotsky (1978), interaction plays a fundamental role in the development of cognition. According to Vygotsky (1978), learning takes place in the zone of proximal development. This zone is the difference between what a child can do alone and what he/she can do with others' assistance. Thus, the child does not learn in isolation therefore the teacher should create room for cooperation amongst students for effective crossfertilization of ideas and knowledge. E-learning is based on the principle that knowledge is co-constructed through interactions with others. According to Vygotsky (1978), everything is learnt through interaction with others and then integrate into the individual's mental structure. The theory of (Vygotsky, 1978) supports the use of e-learning.

\section{Scope of the Study}

The study was limited to third year statistics students at Mukuba University. Mukuba University formerly Copperbelt Secondary Teachers College (COSETCO) is located in the Itimpi area, approximately nineteen point eight (19.8) kilometres from the Kitwe town centre off the Kitwe-Chingola dual carriageway in the Copperbelt Province of Zambia. The study investigated the effect and challenges of e-learning on the third year Mathematics students at Mukuba University. Researches chose Mukuba University because it was the first time to teach distance students at Mukuba University using e-learning.

\section{Limitations}

Limitation is a list of problems that the researcher might encounter concerning, for example, the availability of data, securing permission from the agency/organisation to carry out the study, obtaining the sample, or any other aspect of the study (Kumar, 2011). The following were the limitations of this study: The sample size of the study: The sample size was only sixty (60) students. This was done to the third-year students taking statistics were only sixty. The study lasted three months which was not enough. On view of this, the reliability of the results would be enhanced further by collecting data for a longer period. 


\section{LITERATURE REVIEW}

Main studies have been conducted on the effect of e-learning on the academic performance of learners and challenges learners face while learning using e-learning. Some of the studies conducted on the effect and challenges of e-learning on learners are as follows:

E-learning adopted at Strathmore University positively impacted on students' academic performance (Neema \& Alfred, 2014). The study was conducted at Strathmore University and the tittle of the study is impact of e-learning strategy on students' academic performance at Strathmore University, Kenya. Findings of the study show that the academic performance of learners improves once e-learning is used. This is because students are in charge of their learning and there is more of learner centered learning. Use of e-learning improves students' performance as compared to face-to-face teaching (Oye et al., 2012). The study was conducted in Malaysia and the findings of the study show that students' performance improves if e-learning is used when teaching.

Students are more likely to be more motivated when applying e-learning (Safiyeh, 2015). This is because students are in charge of their learning and in the process, they discover a lot of things on their own and group discussion is enhanced. Group discussion is important as students share ideas and they give each other responsibility of understanding topics. Within their group of discussions, what is important for students is to identify challenges they face in each topic so that lecturers can come in. Success in the implementation of e-learning educational system as one of the main approaches in managing knowledge and educational needs of higher education organization will not be achieved without identifying the different skill, technical and cultural challenges (Leila et al., 2018). E-learning offers a tremendous opportunity by the means of electronic and students can learn at their own pace. Traditional learning is expensive and takes a long time, and the results can vary (Manya et al., 2018). E-learning offers an alternative that is faster, cheaper, and potentially better than traditional way of teaching. E-learning plays an important role in education as it changes the way students' think and study and can help students to grow with a better aptitude.

Results in e-learning are better than Conventional Learning Approach. Cooperative e-learning teaching strategy enhance students' learning in Biology leading to improved achievement compared to conventional methods (Orora et al., 2014), The key in Cooperative e-learning is working together and the group has a clear task or goal so that everyone knows they sink or swim together. The efforts of each person benefit not only the individual, but also everyone else in the group. There is positive interdependence once Cooperative e-Learning is applied as a teaching strategy. Positive interdependence is important for students because students are committed to the work as they want personal success as well as the success of every member of the group. The use of e-learning is effective for students for construction of knowledge and creativity acquisitions (Zare et al., 2016). Creativity is important for students as topics are covered online. E-learning helps students to be creative and to work hard. For example, when using Moodle software, if an assignment is set for two weeks, students should submit the assignment using Moodle within two weeks and those who delays end up failing the assignment as the system cannot allow them to submit. Despite the positive effect of e-learning on academic performance of learners, there are also challenges associated with this teaching strategy. E-learning raises significant challenges to learners on technical part (Rana et al., 2014). Technical challenges may include internet failure or internet do not work according to what academics require. Success in the implementation of E-learning educational system as one of the main approaches in managing knowledge and educational needs of higher education organization will not be achieved without identifying the different skill, technical and cultural challenges (Leila et al., 2018). Cultural challenges should be identified before implementing e-learning because everyone has got their ways of learning based on their culture. For example, those who are used with taught way of learning will have challenges to adapt to E-Learning strategy and their academic performance will be affected negatively. For e-learning to be effectively used, it is important to understand students' learning styles. There are technical training challenges when using e-learning (Islam et al., 2015). Before students use elearning approach, students should be trained on how to learn using e-learning strategy. For example, students should be trained on how to use moodle software to download the lessons and videos. Lecturers should also be trained on how to handle e-learning strategy for it to be a successful leaning strategy. The literature review indicates the challenges of E-Learning and the importance of using e-learning which is learner centered approach of learning which is in support of the Zambian Syllabus of Mathematics. According to Ministry of Education (2013), learner-centered approach or pedagogy approach of learning should be applied in classes when teaching. This involves learners to learn Mathematics in context of multipart, comprehensive and practical problems. Under such learning situations learners may be required to identify what they already know, what they need to know and how and where to access new information that may lead to resolution of the problem. These are some of the challenges faced when using e-learning strategy.

\section{METHODOLOGY}

Different scholars have defined research design differently. For example, (Kothari, 2004) defined research design as a conceptual structure within which the research is conducted. According to Kothari (2004), research design constitutes the blueprint for the collection, measurement and analysis of data. In other ways, research design is a plan, structure and strategy in which the researcher uses to find out alternative tools to solve the problem in the research. The study used quasi-experimental research design because of the sampling method which was used. In this study, purposive sampling approach was used. The research, however, was experimental because its goal was to determine the effect of e-learning on the academic performance of students. Quasi experimental design was used to determine effect of e-learning on the academic performance of Third Year Students in Statistics. This was Pre-test Post-test control group. Questions in the pre-test and post-test were based on Gamma and Beta Function and Probability Distributions of Functions of Random Variables. The experimental group studied Gamma and 
Beta Function and Probability Distributions of Functions of Random Variables using e-learning method where Zoom and WhatsApp were used throughout the lessons while the control group studied Gamma and Beta Function and Probability Distributions of Functions of Random Variables using conventional learning method of teaching. This was done to the fact that there was only one third year statistics class (group) at the university for the 2020 academic year. The study used mix methods approach in order to observe the effect of e-Learning and the challenges of e-Learning. Since the research involved the collection of both qualitative (open-ended) and quantitative (closed-ended) data in response to the research question and hypothesis, qualitative data was gathered from students regarding the challenges they are facing when using e-Learning approach whereas quantitative data was collected using a pre-test and post-test scores. Finding out about students' challenges when using elearning in the learning of statistics was done qualitatively using questionnaire.

The following structure shows the experimental design that was employed in the study.

$$
\begin{array}{lll}
O_{1} & X & O_{2} \\
O_{1} & - & O_{2}
\end{array}
$$

Where;

$>O_{1}$ : Observations made during the pre-test measures. Both the experimental and control group were given the test before the start of the study.

$>\mathbf{X}$ : E-learning approach

$>\boldsymbol{O}_{2}$ : Observations made during the post-test. Both the experimental and the control groups wrote the test after the study.

\section{Target Population}

Different scholars have defined target population differently but with the same meaning. For example, Robert et al. (2004) defined target population as a set of units to be studied. Target population refers to a group of elements or cases, whether individuals, objects, or events that conform to specific criteria and to which researchers are interested in generalizing their conclusions (McMillan \& Schumacher, 2010). The target population of this study included all the third-year students studying statistics (MAT 350) at Mukuba University in the 2020 academic year calendar. Mukuba University has a population of sixty (60) third year students studying (MAT 350) under distance learning.

\section{Sample and Sampling Techniques}

There is only one class for third year Mathematics at Mukuba University who are studying MAT 350. Data were collected using two instruments: a questionnaire and Statistics Performance Test (SPT) instrument. Questionnaire looked at the challenge's students at Mukuba University are facing when learning using E-learning strategy while Statistics Performance Test measured the performance of students in the topics, they were given to learn using e-learning approach and conventional learning approach. The sample for the study comprised sixty (60) third year students. The class was purposively selected to be the research subject. The primary consideration in purposive sampling is the researcher's judgement as to who can provide the best information to achieve the objectives of the study (Kumar, 2011). Since this was a quasi-experimental research design, the experimental group learnt Gamma and Beta Functions, and Probability Distributions of Function of Random Variable using e-learning approach where zoom and WhatsApp was used. The control group learnt Gamma and Beta Functions, and Probability Distributions of Function of Random Variable using conventional learning approach.

\section{Data Collection Instrument, Techniques and Methods}

In this study, the dependent variable was academic performance while the independent variable was e-learning. To assess performance of students in statistics, test questions were prepared by the researchers. Four lectures at Mukuba University validated the questionnaire. Validity is the ability of an instrument to measure what it is designed to measure (Kumar, 2011). In other words, the researcher must obtain the reality of responses of those people who are under the test through comparing their responses with such truth that indeed is truth.

\section{Data Analysis}

Data collected were analyzed using independent sample t-test and thematic patterns. The statistical test used to analyse the data was independent sample t-test since the study was looking at performance of students and data was normally distributed where normality test was conducted at pre-test and post-test level. Given that the quantitative data had met the condition for normality, an independent sample t-test was used with the help of SPSS version 20. One of the methods used to test if the scores are normally distributed is Kolmogorov-Smirnov test (Pallant, 2007). This test for normality is based on the maximum difference between the observed distribution and expected cumulative-normal distribution (Pallant, 2007). The smaller the maximum difference the more likely that the distribution is normal. Qualitative data were analyzed using thematic method.

\section{DATA PRESENTATION, ANALYSIS AND INTERPRETATION}

The following research questions were formulated:

(i) What is the effect of e-learning on students' performance in Statistics?

(ii) What are the challenges involved in the implementation of e-learning in teaching statistics at Mukuba University? 
Table 1. Group statistics

\begin{tabular}{cccccc}
\hline & Group & N & Mean & Std. Deviation & Std. Error Mean \\
\hline \multirow{2}{*}{ Score } & Experimental & 30 & 75.03 & 12.933 & 2.361 \\
\cline { 2 - 6 } & Control & 30 & 59.47 & 17.756 \\
\hline
\end{tabular}

Table 2. Independent samples test

\begin{tabular}{|c|c|c|c|c|c|c|c|c|c|c|}
\hline & & \multicolumn{2}{|c|}{$\begin{array}{c}\text { Levene's Test for } \\
\text { Equality of Variances }\end{array}$} & \multicolumn{7}{|c|}{ t-test for Equality of Means } \\
\hline & & \multirow[t]{2}{*}{$\mathbf{F}$} & \multirow[t]{2}{*}{ Sig. } & \multirow[t]{2}{*}{$\mathbf{t}$} & \multirow[t]{2}{*}{ Df } & \multirow{2}{*}{$\begin{array}{l}\text { Sig. (2- } \\
\text { tailed) }\end{array}$} & \multirow{2}{*}{$\begin{array}{c}\text { Mean } \\
\text { Difference }\end{array}$} & \multirow{2}{*}{$\begin{array}{l}\text { Std. Error } \\
\text { Difference }\end{array}$} & \multicolumn{2}{|c|}{$\begin{array}{c}95 \% \text { Confidence Interval } \\
\text { of the Difference }\end{array}$} \\
\hline & & & & & & & & & Lower & Upper \\
\hline \multirow{2}{*}{ Score } & $\begin{array}{c}\text { Equal variances } \\
\text { assumed }\end{array}$ & .615 & .436 & 3.881 & 58 & .000 & 15.567 & 4.011 & 7.538 & 23.595 \\
\hline & $\begin{array}{c}\text { Equal variances } \\
\text { not assumed }\end{array}$ & & & 3.881 & 53.012 & .000 & 15.567 & 4.011 & 7.522 & 23.611 \\
\hline
\end{tabular}

Table 1 reveals that the mean for the control group was 59.47 while the mean for the experimental group was 75.03 . The standard deviation for the experimental group was 12.933 and the standard deviation for the control group was 17.756 . The experimental group performance mean (75.03) and the control group performance mean (59.47) indicated that the performance of the two groups was not the same.

The level of significance $\alpha$ is the maximum probability for rejecting a true null hypothesis. According to McMillan and Schumacher (2010), the level of significance is used to indicate the probability of being wrong in rejecting the null hypothesis. It is also known as the level of probability (P-level), and is expressed as a decimal. From Table 2, $\alpha=0.05$, using independent sample t-test, since P-value $=0.000<0.05$, we reject $H_{0}$ at 5 percent level of significance and conclude that there is a statistically significant difference in performance of third year students in statistics between students who were taught using e-learning Approach and students taught using Conventional Learning Approach. The results from the study suggested that e-learning has the capacity to improve students' academic performance, which was the research hypothesis of the study.

Results regarding challenges in e-learning implementation were recorded under the following headings:

1. Students' challenges

2. Lecturers' challenges

\section{Students' Challenges}

The following categories were generated using thematic analysis:

1. Limited bundles

2. No motivation

3. Limited access to website

4. Expensive smart phones

5. No training

The frequency of responses for each category were as presented in the bar chart shown in Figure 1.

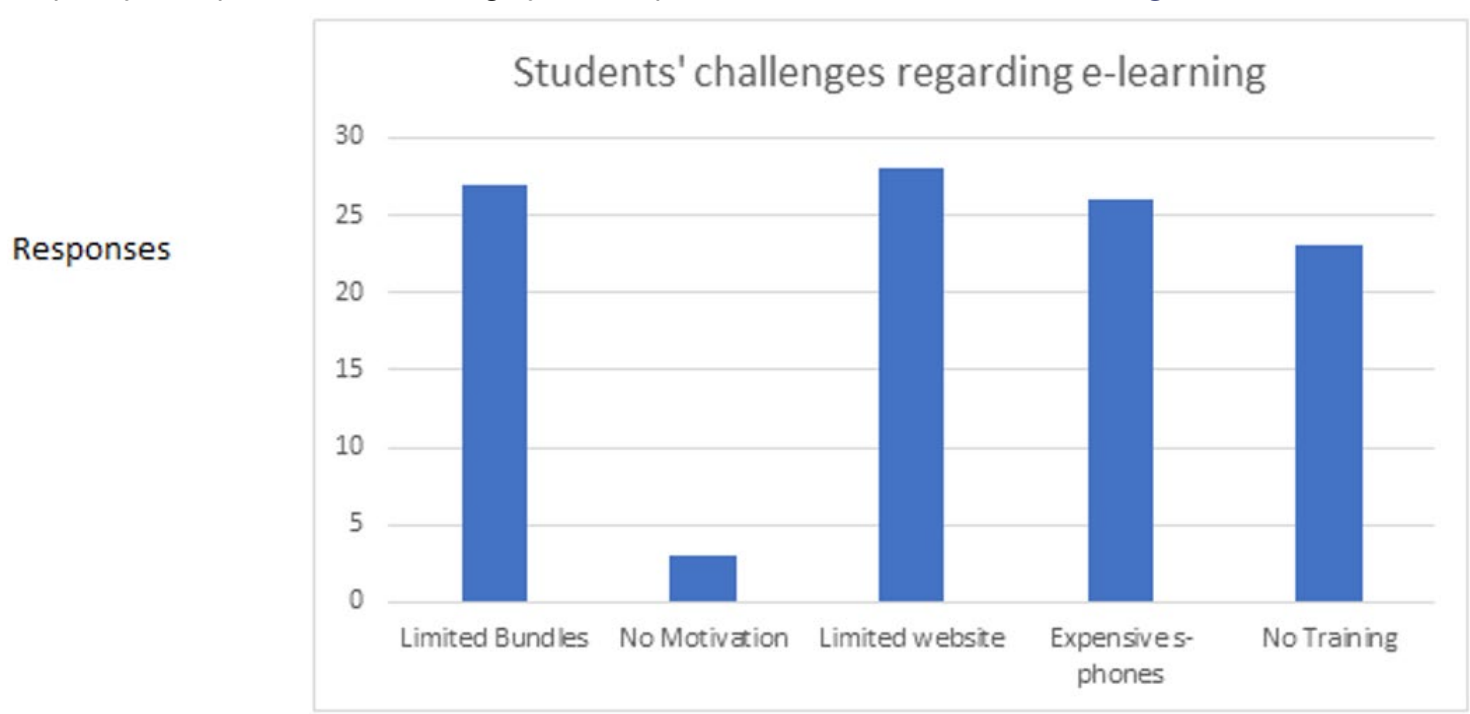

Figure 1. Students' challenges in e-learning 


\section{Lecturers' Challenges}

The following categories were generated using thematic analysis:

1. Limited bundles

2. Limited feedback

3. Limited access to website

4. Laptops expensive

5. Limited time

Lecturers' responses for each category were as presented in the bar chart shown in Figure 2.

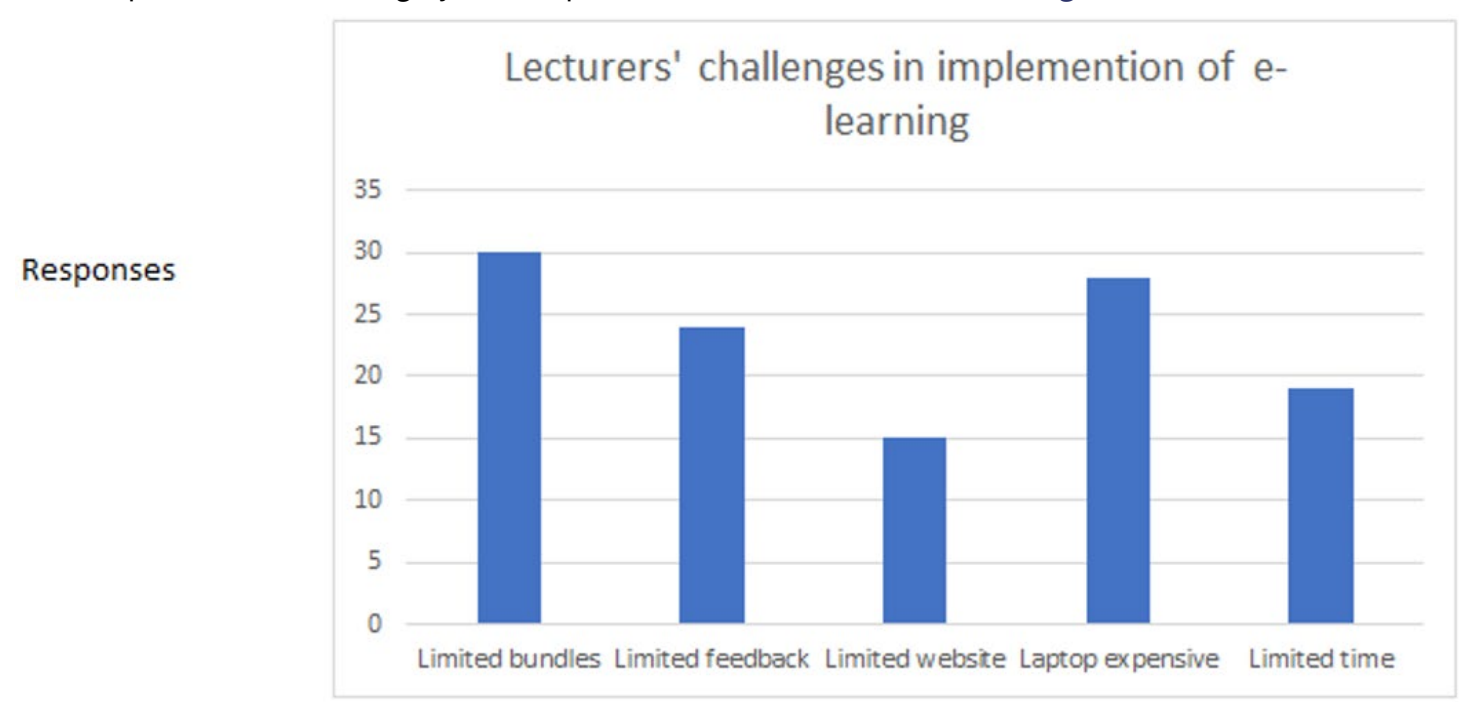

Figure 2. Lecturer' challenges in e-learning implementation

\section{DISCUSSION, CONCLUSION AND RECOMMENDATIONS}

\section{Discussion}

The analysis in Table 2 shows that students performed well in statistics after they learnt statistics using e-learning method of teaching. The results are in line with (Neema \& Alfred, "2014) who concluded that e-learning impacted positively on students' academic performance. E-learning helps students to form group studies for them to understand the topics. From the results of the study, it shows that the use of e-learning is better than face-to-face approach of teaching. This is in line with the results of (Oye et al., 2012) who concluded that the use of e-learning improves students' performance as compared to face-to-face teaching. The improved performance of the students after using e-learning approach is as a result of students being in charge of their learning and there is more of learner centered learning. The results from the study shows that students are more motivated when they learn using e-learning. The results are consistent with the findings of (Safiyeh, 2015) who concluded that students are more likely to be more motivated when applying e-learning. This is because students are in charge of their learning and in the process, they discover a lot of things on their own and group discussion is enhanced. Group discussion is important as students share ideas.

The results from the study shows that e-learning offers a tremendous opportunity by the means of electronic and students can learn at their own pace and the results can be better than traditional method of teaching. Findings from this study are similar with the findings of (Manya et al., 2018) who concluded that traditional learning is expensive and takes a long time, and the results can vary. One key aspect of e-learning is that it offers an alternative that is faster, cheaper, and potentially better than traditional way of teaching. E-learning plays an important role in education as it changes the way students' think and study and can help students to grow with a better aptitude. There is personal and group achievement once e-learning is applied. Once group discussion is formed, the efforts of each person benefit not only the individual, but also everyone else in the group. There is positive interdependence once e-learning is applied as a teaching strategy. Positive interdependence is important for students because students are committed to the work as they want personal success as well as the success of every member of the group. The use of e-learning is effective for students for construction of knowledge and creativity acquisitions (Zare et al., 2016). The results from the study show that there are creativity acquisitions when E-Learning is applied.

Despite the positive effect of e-learning on the academic performance of students, the learning approach has challenges on students and lecturers. E-learning raises significant challenges to learners on technical part. Technical challenges in this study is about internet failure or internet do not work accordingly. Findings of the study are consistent with the findings of (Rana et al., 2014). E-learning was introduced at Mukuba University this year (2020) when there was an outbreak of corona virus. Students have been facing challenges to access Mukuba University website and during the weekend internet has been a problem for students. Twenty-six out of thirty students claimed that the Mukuba website was usually down on weekend and fifteen out of thirty lecturers had the similar challenge. Buying bundles is also a challenge for students because bundles are expensive. All students and 
lecturers who participated in the study claimed that buying bundles to be using in e-learning is expensive. Before using e-learning, different skill, technical and cultural challenges should be identified. The results from the study are in line with the findings of (Leila et al., 2018) who concluded that for E-learning to be a success in the implementation of educational system, different skill, technical and cultural challenges should be identified. Cultural challenges should be identified before implementing E-Learning because everyone has got their ways of learning based on their culture. For example, those who are used with taught way of learning will have challenges to adapt to e-learning strategy and their academic performance will be affected negatively. Not all the students have smart phones and lectures are required to buy laptops and this is a challenge to both students and lecturers. For e-learning to be effectively used, it is important to understand students' learning styles. Mukuba University is using Moodle and some students were not taught on how to use moodle and the training for lectures came after the program started. The findings of the study are in line with the findings of (Islam et al., 2015) who concluded that there are technical training challenges when using e-learning. Before students use e-learning approach, students should be trained on how to learn using e-learning strategy. For example, students should be trained on how to use moodle to download the lessons and videos. Lecturers should also be trained on how to handle e-learning strategy for it to be a successful leaning strategy. There is lack of motivation on the part of students when e-learning is applied as a learning strategy. Some students have paid school feels but they are not registered in the system and it is difficult for them to access e-learning and students are demotivated to learn.

\section{Conclusion}

The study has shown that e-learning strategy has a potential to improve students' academic performance in statistics. The learning approach has a positive effect on the students' academic performance in statistics. The results would imply that incorporating e-learning in the mathematics classroom at Mukuba University would enhance the learning of mathematics.

\section{Recommendations}

The following recommendations were made after the study:

1. E-learning to be integrated with other methods of teaching in the teaching at Mukuba University. Lecturers are encouraged to use e-learning in the teaching.

2. More studies should be conducted on the effect of e-learning in statistics.

Author contributions: All authors have sufficiently contributed to the study, and agreed with the results and conclusions.

Funding: No funding source is reported for this study.

Declaration of interest: No conflict of interest is declared by authors.

\section{REFERENCES}

Auer, M. E., \& Thrasyvoulos, T. (2018). The challenges of the digital transformation in education. Springer.

College, e. (2020). ELearning. Carolina: Elearningnc.gov.

Creswell, J. W. (2014). Research design: Qualitative, quantitative, and mixed methods approaches. SAGE Publications.

Davidson, N., \& Major, C. H. (2014). Boundary crossing: Cooperative learning, collabolative learning, and problem-based learning. Journal on Excellence in College Teaching, 25(3\&4), 7-55.

Islam, N., Beer, M., \& Slack, F. (2015). E-learning challenges faced by academics in higher education: A literature review. Journal of Education and Training Studies, 3(5), 102-112. https://doi.org/10.11114/jets.v3i5.947

Kothari, C. R. (2004). Research methodology. New Age Internation (P) Limited.

Kumar, R. (2011). Research methodology: A step-by-step guide for beginners. SAGE.

Lawless, C. (2018). What is eLearning? Digital Marketing Manager at LearnUpon.

Leila, S., Vahid, C., Esmaeil, M., Azadeh, B., Behrooz, J., \& Mahsa, H. (2018). The challenges of e-learning system: Higher educational institutions perspective. Journal of Education and Health Promotion, 7(1), 116.

Manya, S., Vishnu, P. V., \& Gayathri, R. (2018). Effect of e-learning on academic performance of undergraduate students. Drug Invention Today, 10(9), 1797-1800.

McMillan, J., \& Schumacher, S. (2010). Research in education: Evidence base inquiry (7th Ed.). Pearson Education Inc.

Ministry of Education. (2013). 'O' level mathematics syllabus grades 10 to 12. Ministry of Education, Science, Vocational Training and Early Education.

Neema, A. P., \& Alfred, K. K. (2014). Impact of e-learning strategy on students' academic performance at Strathmore University, Kenya. Makerere Journal of Higher Education, 6(1), 99-108. https://doi.org/10.4314/majohe.v6i1.6

Orora, W., Keraro, F., \& Wachanga, S. W. (2014). Effects of cooperative e-learning teaching strategy on students' achievement in secondary school Biology in Nakuru County, Kenya. Sky Journal of Educational Research, 2(1), 1-9. https://doi.org/10.18488/journal.61/2014.2.6/61.6.137.146

Oye, N. D., lahad, A. N., Madar, M. J., \& Rahim, A. N. (2012). The impact of e-learning on students performance in tertiary institutions. International Journal of Computer Networks and Wireless Communications, 2(2), 121-130.

Pallant, J. (2007). SPSS survival manual: A step by step to data analysis using SPSS for Windows (Version 15). Allen and Unwin. 
Rana, H., Rajiv, \& Lal, M. (2014). E-learning: Issues and Challenges. International Journal of Computer Applications, 97(5), $20-24$. https://doi.org/10.5120/17004-7154

Robert, G. M., Floyd, F. J., Mick, C. P., James, L. M., Eleanor, S., \& Roger, T. (2004). Survey methodology. John Wiley \& Sons, Inc.

Safiyeh, R. H. (2015). Effects of e-learning on students' motivation. In 3rd International Conference on Leadership, Technology and Innovation Management (pp. 423-430). Elsevier Ltd. https://doi.org/10.1016/j.sbspro.2015.04.905

Saul, M. (2018). Simply psychology. University of Manchester.

Tichapondwa, S. M. (2013). Preparing your dissertation at a distance: A research guide. Virtual University for Small States of Collonwealth-Vancouver.

Vygotsky, L. S. (1978). Mind in society: The development of higher psychological processes. Harvard University Press.

Zare, M., Sarikhani, R., Salari, M., \& Mansouri, V. (2016). The impact of e-learning on university students' academic achievement creativity. Journal of Technical Education and Training, 8(1), 25-33. 